\title{
AL DECIR ESTO EN LO DICHO DE LA GRAMÁTICA LINGÜÍSTICA
}

\author{
Antonio Domínguez Rey \\ (Universidad Nacional de Educación a Distancia)
}

Al hablar de los pronombres demostrativos, resaltamos la deixis espacial o temporal de sus formas en relación con el proceso locutivo. Retenemos la mostración, que puede ser referencial exógena, hacia las cosas, o endógena, hacia el discurso en que se encuadra. Apenas recordamos, sin embargo, el carácter etimológico del mostrar, que es el mismo de monstrum, y que coincide además con el del verbo latino moneo, donde está presente, a su vez, la raíz *men, relacionada con la atención del pensamiento hacia algo.

Tampoco nos fijamos en el prefijo de que antecede a la mostración. Hay en él un sentido de origen o punto inicial de proceso ya un tanto lejano, así como de consecuencia, pero también, al menos en sus sombras iniciales, un rasgo direccional de arriba hacia abajo. Si a la diacronía nos atenemos, en la palabra demostrativo encontramos, además de la deixis funcional, una intención dirigida hacia algo de nivel más bajo que la posición locutiva. Este hecho resulta importante y requiere otra atención respecto al fenómeno deíctico. 
Por otra parte, las gramáticas resaltan la relación de los demostrativos con el sistema pronominal de persona. Asocian una persona locutiva a su base. A los demostrativos les corresponde la tercera, pero indican también, dentro de su órbita, relación con alguna de las personas gramaticales (Alarcos 1994: 92). He aquí otro dato revelador, pues si la tercera, la más impersonal de todas, es el campo de las objetivaciones, resulta que el hablante lo mide espacial y temporalmente desde el punto de habla.

En cuanto a la forma neutra, que acota y reduce la referencia inmediata, de variación desinencial fija en español para el género y el número que interiorizan, los valores temporales del aquí y ahora del habla son evidentes: esto-aquí/ahora, eso-ahí/ahora, aquello-allí(allá)/ahora, pero también, para la segunda y tercera personas, el tiempo correspondiente: eso-ahí/antes-después, aquello-allí(allá)/antes-después.

Parece, por tanto, que, de las tres formas, la segunda y tercera toman posiciones respecto del aquí-ahora básico y locutivo de esto. A la dimensión espacial externa le corresponde otra, pues, interna: a la extensión del espacio, la de la memoria. Surge así una dirección longitudinal del espacio y del tiempo a la par de aquella otra, vertical, sugerida por el prefijo de. Tendríamos entonces un curioso sistema ortogonal, como si el espacio y el tiempo se recubrieran mutuamente, designando el espacio la distancia del tiempo y, viceversa, la duración de éste, internamente sincretizada, la extensión objetiva. Asoma con ello el horizonte semiótico y fenomenológico del lenguaje.

G. Guillaume (1982: 52) observó que toda persona gramatical encierra, convertido, el espacio de tercera, la persona lógica siempre existente, pero acabamos de ver que ésta remite, a su vez, a las otras dos. Se implican, por tanto. Al hablar, el emisor y el receptor figuran también como objetos referidos de los que se habla. Ahora bien, suponiendo ya la posición de tercera un distanciamiento en relación al punto de habla, ese espacio descubre otro interno entre el objeto de destino, el destinatario, y el remitente, la persona que habla. Tal espacio del espacio es la dimensión interna y contemplativa del lenguaje. Volveremos sobre él más avanzados.

Diciendo esto, eso, aquello, esto de aquí, eso de ahí, aquello de allá, o esto de antes, de después, eso de entonces, de luego, etc., incluso con interferencias posibles de otros ejes no tan uniformes, ya acontecen dos fenómenos cartesianos. Por una parte, el cumplimiento deíctico de esto en la demostración, lo que llena su vacío, su objeto, susceptible de 
verificación locutiva. Por otra, la distancia o fundamento locutivo de tercera persona respecto de la primera dicente, donde esto se manifiesta como forma móvil y objetiva en la conciencia hablante: una forma-objeto. En cuanto dicho, hay debajo de ella un decir implícito. Observamos la distancia locutiva de ego a la forma vacía que busca contenido y, en tal distancia, apreciamos su carácter móvil, su independencia respecto de un contenido determinado.

Parece, pues, como que reflejara las dos dimensiones, una el espacio discriminado por su forma, el discernimiento de una extensión nominal que le corresponde, según G. Guillaume, en cuanto soporte independizado o liberado por el aporte (1985: 62); otra, la dimensión formante, mi intuición - la de cualquiera - de esa forma sin aporte, vacía, que es ahora objeto intuido en la persona hablante. Pero la cuestión se complica un poco más si consideramos que el espacio discriminado por la dimensión formante, que también se manifiesta como dirección hacia algo —ofrece a su vez distancia-, no desaparece porque no haya un cumplimiento concreto. Puede ser uno, otro o ninguno. Nos situamos, entonces, ante un embrollo de espacios y objetividades. Entre la conciencia locutiva y el cumplimiento impletivo de esto habría dos instancias o momentos. ¿Cómo surge una objetividad dentro de otra que la recubre?

El problema deriva de la significación de la palabra esto. Lo intuido en ella es bien cosa externa, designable, un objeto de la realidad sensible, bien un objeto implicado en el discurso o bien, sencillamente, una ausencia de cosa u objeto. En el segundo caso, el demostrativo esto es unidad sincrética que implica y explica tiempo, es decir, discurso efectuado, efectuándose o en potencia de efecto. Si hay, en cambio, ausencia, nos quedamos con la forma pura de la palabra, y ya sabemos que aún encierra en sí una dimensión locutiva entre tercera y primera persona.

¿Qué sucede con esta objetividad que se prolonga o suspende en otra? Acontece la significación, el llevar el signo esto de un lugar o tiempo a otro. La intuición formal se tiene a sí misma como campo de objetivación o formalizante y, en tal tenerse, ocupa, emplea el espaciotiempo de conciencia que le corresponde. Su espacio es tiempo, o viceversa. Pero esta duración pertenece a toda palabra como forma o signo que significa. Constituye su carácter pronominal, su salida hacia el nombre, sea nombre sustantivo, nombre verbo o nombre pronombre. Toda palabra pronombra. Su propio nacimiento fue pro-nombre, una dirección formal de conciencia hacia un contenido intuido primero como espaciotiempo 
de objetivaciones. A esto se refieren las distintas denominaciones del pronombre desde la «capacitas formarum» de Duns Scoto. Al acto objetivante, nominal, precede otro de fondo, intencional, que funda, en su tensión, la forma formante. Cuando un hablante efectúa un signo, hace presente su objetividad, pero activa, en el mismo acto, el despliegue de su curso, la forma que lo formaliza dando nombre a algo. Por eso corregimos si lo intuido no cuadra con ella. Ahora bien, la intención formalizante, pronominal, supone que algo, un esto, se presenta en su camino: esto - este algo - es un árbol, un libro; o también: con esto, señalado de algún modo y, entonces, el lenguaje sale de sí hacia otro, en plano de lengua, o remite a sí mismo, en discurso.

Hegel advirtió que la simple presencia de lo inmediato se da en la conciencia esciente mediante una distinción fundamental operada en el plano objetivo de todo saber: el éste-yo y el esto-objeto. La percepción más simple pasa entonces por un estadio demostrativo. El prefijo de adquiere aquí también su fuerza etimológica de proceso a partir de un punto y dirigido a una consecuencia inmediata. Entre los dos estos - adviértase en esta designación plural el fondo de cuanto decimos - hay una relación inmediata que descubre, en el mismo instante, la mutua mediatez de la diferencia. Uno, el yo, es por relación al otro, el objeto, siendo ambos, a fin de cuentas, una de-mostración simultánea, pues resultan de la misma posición natural del ser como certeza sensible (Hegel, 1966: 63). Surgen en el espacio intermedio del guión o espacio vacío de esto. Vacío porque la donación de su contenido acaece precisamente negando aquél con que se muestra ${ }^{1}$, porque no es realmente el dado ${ }^{2}$.

Esto contiene un ahora y un aquí cuyas concreciones objetivas, sus deixis, no son su propio contenido. Al decir «Esto es un árbol», supo-

1 Hay en esto una coincidencia notable de G. Guillaume con Hegel. En primer lugar, recordemos la dimensión locutiva de tercera persona inscrita en todo ego dicente. En segundo, la tercera también es objetivada desde las otras dos por razones de espacio y tiempo. Pero hay otra aún más importante. La tercera persona es la que no habla y a la que nadie habla, una persona, dice G. Guillaume, «hors langage, une persone négative du côté langage..., qui est donc troisième sous un rang de langage inexistant» (1982: 52).

2 El no ser de lo manifestado o dicho implica un supuesto o «impensado», en sentido fenomenológico, que también subtiende la acción del decir. Lingüísticamente, la idea es muy antigua. La encontramos en el primer fragmento del Tao-tö-king, de Laozi. Al no ser ningún nombre eterno —en el caso de Hegel, al no nombrar ninguno el singular concreto-, queda siempre lo innominado como un resto inmenso del lenguaje. Ahora bien, la distinción de las cosas acaece con el nombre, al nombrarlas, e incluso la sustancia se revela en un perenne no-ser. Y tal es también el trasfondo pronominal de esto en Hegel. 
nemos un ahora y un aquí del ser en cuestión cuya esencia no se agota en el árbol dado, porque la trascienden en su capacidad supositiva. El pronombre esto contiene un adverbio de tiempo y otro de lugar, fundidos. El no agotarse de su esencia en el contenido que designan supone, a su vez, una negación de lo afirmado. En tal acto negativo se descubre realmente la simplicidad mediada de Hegel como universalidad (1966: 65).

Hegel observa en este acto simple de la afirmación pronominal una suposición nunca demostrada y que el lenguaje tampoco puede enunciar porque se mantiene en la universalidad del esto referido. La indicación adverbial de su aquí y ahora no es el punto que suponemos, el singular árbol, sino el movimiento relacional de todos los aquí y ahora, «muchos aquí», «un simple conjunto de muchos aquí» y «una pluralidad de ahoras compendiada» (Hegel, 1966: 68, 70). El singular negado como contenido de esto antepone, por tanto, en su colectividad de lugares y tiempos, un todo previo ya dado de algún modo en la presencia simple de cuanto se manifiesta, del ser algo, ser esto, aquí, ahora, etc. En todo esto hay un otro que no es este singular presente. $\mathrm{Y}$ tal otro manifiesta la universalidad indicativa que lo define. El singular sensible es supuesto e «inasequible al lenguaje, que pertenece a la conciencia, a lo universal en sí». Y todo esto implica, a su vez, algo sustancial y sorprendente para lo aquí tratado. Si quisiéramos decir lo singular, «bajo el intento real de decirlo se desintegraría; quienes comenzaran a describirlo no podrían acabar su descripción, sino que deberían dejarlo a cargo de otros, los cuales tendrían que reconocer ellos mismos, a la postre, que hablaban de una cosa que no es» (Hegel, 1966: 70).

En esto existe algo aludido que no se puede decir, porque todo dicho suyo es también un no-ser. Esto presupone una diferencia negativa de multiplicidad implicada. Y ello resulta del movimiento y duración que lo constituye. La demostración lingüística nos habla, en consecuencia, de un espacio objetivo non dicendum, pero aludido como supuesto. Tal suposición, indecible e indemostrable, es, no obstante, lo que no permanece de lo supuesto. Si permaneciera, todo aquí y ahora serían este árbol, como todo yo sería mi yo, y así sucesivamente. Esto remite sólo a la relación denominativa o pro-nominal. Todo nombre y todo objeto son un esto antecedente. La conciencia pro-nominaliza. Atraviesa mentalmente el espacio objetivo presentando y su movimiento se transita como forma relacional cuyo contenido niega cuanto no sea el horizonte de su capacidad relativa. Puede decirse, incluso, que la conciencia 
es pro-nombre: tendencia a nombrar las cosas. En su no-ser cabe la concretud singular de todo ente. Se explica así la extensión ilimitada y significativa del pro-nombre.

La suposición pronominal posibilita en Hegel el acto sintético de la percepción como referencia de lo múltiple a lo uno. Establece, pues, la base relacional de un juicio. Recordemos ahora el eje ortogonal y cartesiano del espacio y el tiempo antes citado. La diferencia entre ésteyo y esto-cosa en el continuo sensible de la existencia acota, cuando menos, un pre-juicio o juicio antepredicativo. $\mathrm{Al}$ saber que el árbol no es el ahora y el aquí de esto, sino un singular suyo entre otros también aquí y ahora, se manifiesta también la distinción entre esto-algo y otro. Ambos extremos se dan dialéctica, inmediata y mutuamente como mediados. La consecuencia es sólo analítica y descriptiva. Sin embargo, la mera mostración de esto supone la tesis de algo-esto o esto-X, posición aún no determinada, es cierto, pero ya en trance y en búsqueda de predicado. Tiene el molde vacío de la relación predicativa. Por eso lo llamamos de-mostrativo.

Esto descubre así una tensión predicativa e interna. Tenemos el numerador de una fracción sin denominador concreto, la dirección de algo como esto hacia otra determinación suya, de donde surge, en realidad, el espacio sintagmático del discurso. Pareciera, a veces, que hay sujeto antes que predicado $y$, otras, predicado antes que sujeto. No hemos salido, sin embargo, de la misma dimensión esto. Son dos direcciones dialécticas que concurren en una misma palabra. Sujeto en cuanto se nombra algo presente en la certeza sensible - sabemos que algo existe-, pero el nombrar ya coincide con la búsqueda de una determinación aún no concreta: predica de algo. Por esto es pro-nombre y, en cuanto tal, implica diátasis - tensión-y diástesis, separación o intervalo. Esta tendencia separadora de entretiempos refleja muy bien su carácter procesivo y refuerza la base pronominal de toda palabra en cuanto signo. Consiste éste también en presentar la ausencia de cuanto refiere y nombra, como vieron A. G. Baumgarten, F. Nietzsche, H. Taine, E. Husserl y, a partir de ellos, E. Lévinas, J. P. Sartre, J. Lacan, R. Barthes y J. Derrida. En su fundamento hay una conciencia pro-nominal.

Se explican así también las vacilaciones de los gramáticos y lingüistas al definir el pronombre desde una base sólo funcional y conmutativa. Por ejemplo, el carácter móvil resaltado por $\mathbf{M}$. Bréal, quien le atribuye además un rasgo instintivo y gestual —eco de los adverbios aquí y ahora. Lo considera incluso anterior al sustantivo y precedente 
de las categorías (Bréal, 1982: 192). Los comparatistas han visto siempre en estas formas un refugio de los elementos primitivos del lenguaje y también, como F. Mistell, seguidor de Steinthal, el sentido formal que actúa en la formación del concepto (Gabelentz, 1984: 340). A este sentido originario remite también $\mathrm{H}$. Paul al situar los pronombres en las raíces primitivas, casi pegadas a las cosas, y como sustitutos formales de sus géneros (Paul, 1968: 264).

El carácter arcaico (Guillaume, 1982: 47), resto aún apreciable en el prefijo pro del pro-nombre, así como su doble valor subjetivo y predicativo, explican también la vacilación de los gramáticos a la hora de considerarlo categoría propia o una clase de nombres, como hace A. Bello (1978: 98), o incluso categoría mixta, nombre y verbo a la vez, como es el caso de J. Vendryes (1968: 135-136). Gabelentz observa también pronombres conjugados como verbos en lenguas melanesias y el paso de la indeterminación a la determinación, lo que diríamos hoy de la significación relacional a su cumplimiento intuitivo, es un ejemplo para él del proceso constitutivo del lenguaje (Gabelentz, 1984: 345). En el pronombre resalta, como en ninguna otra parte, su forma interna.

Pero donde mejor apreciamos el carácter nominativo y proverbal es en el discurso. En él asistimos a la distancia de la forma a su referente o a la acción discursiva. Despliega un valor doble, ana y catafórico. Su capacidad fórica de retomar el discurso o una parte suya lo nominaliza o verbaliza como predicado sincrético. Convierte una acción o estado de cosas, un enunciado, en categoría nominal transitiva respecto del discurso e intransitiva en su propia significación, pues remite a un «mismo», nunca igual, presentado con otra forma. El nombre y el verbo se fijan en pro-nombre ante-predicativo dentro de una predicación supuesta. Esto remite a algo, a su propio referente, como relativo suyo. Su cosa es el estado de la cosa, la procesualidad del discurso. Dicho de otro modo, su contenido es el proceso relacionante de la forma.

La referencia nominal se curva entonces en transición discursiva y ésta revierte a aquélla otorgándole un contenido de discurso. El núcleo queda aparentemente vacío, pero en realidad lo llena la forma procesual de la nominalización, el fondo transitivo del nombre, al que pertenece también la relación discursiva. En esto confluyen potencialmente sintagma y paradigma, sus reductos sintácticos. Tal es la identidad o estado de mismo que hay en esto al ser procesado en discurso. 
Este eje ortogonal pertenece a cualquier nombre, pero las formas de apariencia vacía lo revelan de modo manifiesto. La materia es aquí también, de algún modo, forma, porque contiene el algo que determina a la intención como núcleo: el estado de la cosa, su objeto. Puede decirse, entonces, que esto es una proposición en cuanto tenor que ha recibido una forma categorial, según la define Husserl (1957: 393), aunque diferente de la proposición copulativa, pues sólo marca la posición. No es lo mismo percibir un objeto con los sentidos, o representarlo mencionándolo, que comprender la atribución lógica de un juicio (Husserl, 1967: 278-279). Entre una mención y un juicio, como entre una designación y una proposición, hay, qué duda cabe, una diferencia cualitativa. La cualidad que expresa el juicio de una situación objetiva no pasa al contenido del acto que la mienta. Sin embargo, dice Husserl, tan pronto aparece "el elemento significativo correspondiente al articulo determinado», esté éste presente o no, equivalen entre sí el nombre, una proposición nominal y esto, sin que sean, por ello, juicios (Husserl, 1967: 278).

Resulta extraño considerar una posición pura y dóxica sin tendencia a recibir algún predicamento, sobre todo si en la tesis resalta una tensión alterativa, según veíamos con Hegel. En la mención nominal de un estado de cosas dado mediante juicio, y designado bien con esto, bien con $E l$ hecho de que, o con Que $S$ es $p$, lo mencionado va incurso como componente antepredicativo y lo reconocemos como dicho de un decir todavía en proceso. Su representación se ajusta a lo representado. Si no fuera así, no reconoceríamos el estado de las cosas como hecho, como esto o como que, forma dicente por excelencia. La síntesis de un juicio englobado como referente de un nombre no deja de ser sujeto predicativo de éste. Todo él equivale a una materia ya dotada de forma susceptible de otra nueva, como reconoce el propio Husserl (1967: 277). Su nombre, indicativo y no judicativo, según él, es también para nosotros atribución nueva dada a la síntesis, por mucho que tal nombre pudiera ser otro $y$, de hecho, lo es en cualquier otro idioma. Adquiere así valor, al menos, de proto-tesis dóxica en cuanto sersupuesto de una forma pro-nominal y antepredicativa. Esta nueva figura noemática de Husserl (1976: 260) se adapta mejor a la realidad del pronombre considerado, pues, si bien no tiene, aislado, una esencia fija, no cabe duda que le corresponde una «vivencia primitiva», ya que ningún pronombre existe fuera de un discurso real o posible.

La lingüística ya observó este fenómeno en la evolución a materia locutiva de numerales, preposiciones y pronombres, sin relación lógica 
en éstos y los primeros, como señala F. Müller (Gabelentz, 1984: 339). En cuanto nominal, esto comporta, siguiendo aquí a Hegel, una suposición antepredicativa en tanto actúa un componente formal relativo.

A decir verdad, si los pronombres son intermedios entre nombre y verbo; si además recubren adverbios de lugar y tiempo; si proceden o estuvieron próximos a raíces pegadas a las cosas, según $\mathrm{H}$. Paul, nada extraño entonces esa dimensión locutiva y móvil que les permite recorrer y delimitar tanto la extensión nominal como la del verbo. Ahora bien, este componente formal procede, como forma interna, del espacio objetivante y alterativo que ya encierra en sí la forma esto. El discurso viene intencionado desde la raíz misma de la palabra como pronombre ${ }^{3}$. La mención evocadora trae a presencia algo ya dado, pero en el decurso de ese acto actúa asimismo la tensión dicente de la palabra. Los demostrativos designan también la distancia del signo al referente, su acción o movimiento dialéctico, así como la progresión perceptiva y expresiva del discurso. Por eso se relaciona esto con el que dicente en tanto anafórico suyo. Son marcas de la reduplicación y del metalenguaje discursivo.

La tensión antepredicativa de esto disuelve la hipóstasis de un estado nominal concebido como acotación de un acontecimiento. La forma interna del lenguaje, discursiva, permite fragmentar el cerco estático con determinaciones concretas, aproximándose y reduciendo, cada vez más, el campo supositivo del que parte. No hablamos con palabras, advierte E. Benot, «sino con su combinación» (1991: 80), y unas determinan a otras. La determinación es, por tanto, ley general del lenguaje y un ejemplo suyo de componente formal sería, como observamos, el neutro esto ${ }^{4}$. He ahí la explicación de su carácter intermedio e, incluso, de su valor neutro, pues atiende sobremanera a los ejes internos que cruzan el lenguaje. Es bifronte, mitad verbo, mitad sustantivo, pero también alza y baja la mirada extendiendo y reduciendo el horizonte de la significación. En su decurso, desentraña

3 De hecho, la raíz - - - del demostrativo contenía — ¿contiene aún?- una apelación fórica de segunda persona. Era decir mostrativo de un dicho para alguien.

4 Benot aplica a la determinación genérica de la palabra los dos principios lógicos ya tradicionales, la extensión y la comprensión (1991: 21-22), adelantándose a los ejes semánticos de las gramáticas estructural y generativa, según se hacía ya en los estudios lógicos desde la antiguiedad. Como todos los gramáticos, cree que, mediante este eje, también ortogonal, se reduce la suposición hegeliana hasta el punto de su individualidad. Lo evocado, ya conocido, se supone, de los interlocutores, favorece la ABREVIA$C I O ́ N$ de las situaciones y de las palabras. Tratándose de un médico ya conocido, la palabra «Médico, en este caso, es una ABREVIACIÓN» (1991: 41). Así serían inicialmente, se entiende, los pronombres, cruces de extensión comprehensiva. 
valores amalgamados. No pierde rango mostrativo, pero lo efectúa en niveles diversos, convirtiendo la lengua en discurso.

Si en esto hay un él o ello incurso delimitado por un aquí y ahora, su referente será siempre universal de simplicidad mediada, nos decía Hegel. De ahí el vano empeño de todo discurso al querer reducir la suposición del comienzo y pretender cosificar así la expresión que lo sostiene. Para Hegel, el discurso «tiene la naturaleza divina de invertir inmediatamente la suposición para convertirla en algo distinto y no dejar, así, que se exprese en modo alguno en palabras» (Hegel, 1966: 70). La simplicidad aludida pasa, no obstante, por la negación de una presencia y ese algo presente está siendo ahí, antes de toda negación, aunque no lo comprendamos, sino que sólo sepamos de él en cuanto noticia sensible, está siendo, decimos, un hay. Lo acotamos en la fugaz permanencia del aquí-ahora referido a su ausencia. La entidad luego concebida como universal simple de muchos aquí y ahora, según Hegel, o la tesis unirradial de un «modo plurirradial de conciencia» previa, como entiende Husserl (1967: 277), no anulan la existencia eliativa, del pronombre él más el adverbio latino ibi y el verbo habeo, que, con la $i$ reducida de aquél, da en castellano el impersonal hay (Pidal, 1968: 303, 333), el il y a francés explicitado por E. Lévinas como fondo inaprensible de todas las categorías, de «neutralidad inhumana», y que tanto el pensamiento como el lenguaje, sobre todo éste, hipostasian y sobrepujan desde el ser mismo, más fuerte, incluso, que la negación (Lévinas, 1986: 11). Cada forma suya ya sería un sometimiento, nunca concluido, de la existencia a sí misma ${ }^{5}$. Y el pro-nombre es, en tal horizonte, el sometimiento máximo del lenguaje a su propia determinación general, sin que nunca resulte, sin embargo, reducido, como evidencia la forma esto.

Así pues, la ausencia radical del pro-nombre manifiesta el proceso dicente y existencial del lenguaje. Diluye el fondo entitativo en emergencia formalizante. Al nominalizar, dice Lévinas (1986: 18, 169), el verbo transmuta en sustantivo y el nombre así dado deshace el anonimato genérico de la palabra. Es nombre con verbo implícito, un verbo de existencia: hay. Lo singular suyo no es, por tanto, la entidad referida, un esto a la mano, sino el acto dicente, la acción verbal.

5 No es éste lugar adecuado para analizarlo, pero téngase en cuenta que el pronombre de tercera aquí aludido, en forma él o $i l$, son acusativos diacrónicos, por tanto casos o caídas semánticas del nombre en dirección hacia alguien o algo. Esta función tan apelativa cuanto objetiva está presente, como un reducto, en el fondo de tales lenguas. 
Si, como observa Husserl, esto significa lo mismo que que $S$ es $p$ o el hecho, la circunstancia, etc., de que S sea p (1967: 278), la hipóstasis del pro-nombre entra en paradigma nominal y contiene también un acontecimiento, la eferencia alterativa y relacionante de Otro que él mismo. A este acontecer de la unidad existencial del movimiento alterativo lo denominamos pro-nombre. En cuanto tal, ya personaliza. La persona le viene del lugar temporalizado o del tiempo acotado como articulación sentiente o Leiblichkeit, en acepción husserliana. El universal entitativo se singulariza en la voz articulada. El cuerpo hace sentir como resonancia universal la articulación concreta del signo. El espacio objetivo de la significación acontece en el yo locutivo que atrae lo Otro a sí sin disolverlo y descubriéndose como palabra eferente. Del universal hegeliano del discurso predica la carne sentiente de los interlocutores, cada uno según su propia capacidad de resonancia fónica.

Sabemos, con todo, que el singular fónico nunca será el universal semántico, ni la socorrida deixis el esto a la mano, ni el Da del Dasein el lugar concreto de la existencia. El ser dado en el lenguaje supone un ser de confianza anterior a la suposición dóxica de Hegel. Esa confianza está en la persona locutiva, que, por serlo, ya depende de otra. É. Benveniste advierte, por ello, que la deixis no basta para definir los demostrativos si no asociamos una «ostensión simultánea» a un indicador de persona. Su autorreferencia delimita el carácter «cada vez único y particular» del demostrativo, su instancia, o estancia, podemos decir, de aquí y ahora singulares. $O$ bien la palabra lleva implícito un decir pro-nominal, o toda indicación suya, la más concreta, es siempre universal. Y no porque la lengua alcance así el discurso, según venimos diciendo con É. Benveniste (1966: 254), sino porque el discurso está en la base de la lengua. Lingüistas y gramáticos parten de una reducción de la actitud natural y existencial del lenguaje, sin saberlo, y sin efectuar la retroversión necesaria o Rückhehre, donde obtenemos su verdadero y originario valor significativo. La singularidad es asunto del individuo, de su participación y apropiación eferente del discurso, es decir, de la Sinnesartikulation.

En tanto deíctico, esto presenta, por tanto, algo más ad aures que ad oculos, según describe K. Bühler estas unidades. Incluso la deixis en phantasma, heredera, a nuestro juicio, de la suposición de Hegel, pertenece al a priori locutivo del lenguaje. K. Bühler no olvida la actitud natural antes citada. Al contrario, la hace explícita desde el inicio de su gran obra: «el momento dramático está preparado en todo decir que 
presenta intuitivamente, y algo de él resulta aprehensible conceptualmente en la deixis en phantasma» (Bühler, 1979: 75). Este momento dramático, dialogal, estaría «fundado en la raíz de la representación lingüística» (Ibid.: 141) y entra en él también, de algún modo, como en el campo mostrativo de un actor, la deixis ad oculos (Ibid.: 144). Ojos, por cierto, ya mentales, semióticos, pro-nominales.

El pronomnre esto nos permite ver así el interior del signo lingüístico, su funcionamiento y hasta tal vez el modo de su origen, «las potencias», como las denomina J. Ortega y Gasset, «genitrices del lenguaje» (1972: 202). El ser o estar en función de otra cosa es la esencia o ser en propio del lenguaje. Por eso usamos aquí el concepto de gramática lingüística o estudio actualizado de sus fundamentos verbales. Su carácter neutro y suspensivo es, en realidad, ponente y tético. Esto evoca, incluso cuando designa, un dicho del que predica reduciéndolo y, por ende, argumentándolo. Mirando a lo dicho, lo tematiza en vacío, como huella y anáfora suya, pero en el decir se llena de tensión dicente, pronominal ${ }^{6}$. La novedad a que alude Husserl en los actos nominales no esquiva el decir nuevo que la retracción supone suspendiendo lo dicho. Lo está interpretando. Ahí ya comienza la hermenéutica, donde situamos también a la gramática lingüística ${ }^{7}$. Educe actos mentales que crean formas desde el lenguaje mismo. El metalenguaje consiste en algo más que referir una forma ya enunciada, pues el lenguaje revierte sobre sí de continuo en nuevas actuaciones. El pronombre

${ }^{6}$ La neutralización suspende activando huellas, pero la huella de esto difiere de la interpretación dada por la gramática generativa. La ausencia lingüística relaciona sin que comande necesariamente. En el caso estudiado, la Categoría Rectora no sería la misma en la oración previa, ya dicha, y en la dicente. Así lo veíamos también con Husserl. Esto es +anafórico y +pronominal, como las categorías vacías, pero representa en discurso una cláusula reducida o categoría llena, fónica. Tendríamos, por tanto, otro problema añadido. La solución generativa es de foco alterno y recurre a la socorrida relevancia del discurso, como hacen, por ejemplo, G. Lorenzo y V. Manuel Longa (1996: 197). Pero esto presupone considerar dos tiempos o dos direcciones alternas, no simultáneas (Ibid.: 194), en PRO. Aplicadas a esto, mientras mirara a lo dicho, no sería dicente, pronominal, siendo así que toda proto-tesis noética supone «intacta la vivencia primitiva en cuanto a su esencia total», salvadas las necesarias modificaciones que el cambio transpositivo implica, nos dice Husserl (1976: 260-261). ¿Sería esto una de tales transformaciones? ¿Y lo intacto suyo? Las direcciones alternas suponen aún neutralizaciones sucesivas: mirar a una parte olvidando la otra. El caso de esto parece manifestarse de otro modo.

7 Toda gramática es, en este sentido, formalización singular de una lengua. Ninguna tipología general puede resumir el compendio de todas las existentes, porque cada una apropia la acción verbal conforme a modos específicos de comprensión que remiten más allá de una tipología. Sólo una Gramática General, que ha de ser linguiística, puede dar razón del verdadero trasfondo del lenguaje. Verdadero por cuanto habrá de educir los principios que la suposición requiere y esto ya presupone recibir el mundo como interpretado. 
esto, forma de las más curiosas de la lengua, nos abre así al estado de las cosas - Sachverhalt de Husserl-y a la mente que las considera.

\section{Referencias bibliográficas}

Alarcos LloraCH, E. (1994). Gramática de la Lengua Española. Madrid: Espasa Calpe.

Bello, A. (1978). Gramática de la Lengua Castellana. Madrid: Edaf.

BENOT, E. (1991). Arte de Hablar. Gramática Filosófica de la Lengua Castellana. Barcelona: Anthropos.

Benveniste, É. (1966). Problèmes de Linguistique Générale, 1. París: Gallimard.

BréAl, M. (1982). Essai de Sémantique (Science des Significations). Brionne: Gérad Monfort.

BÜHLER, K. (1979). Teoría del Lenguaje. Madrid: Alianza Universidad.

GABELENTZ, G. VON DER. (1984). Die Sprachwissenschaft. Ihre Aufgaben, Methoden und bisherigen Ergebnisse. Tübingen: Gunter Narr Verlag.

HegEL, G. W. F. (1966). Fenomenología del Espíritu. México: FCE.

HUSSERL, E. (1957). Logique Formalle et Logique Transcendantale. París: PUF. - (1967). Investigaciones Lógicas, II. Madrid: Revista de Occidente.

- (1976). Ideen zu einer reinen Phänomenologie und phänomenologischen Philosophie. B. III/1. The Hague: Martinus Nijhoff.

LÉvinas, E. (1986). De l'Existence à l'Existant. París: Vrin.

Lorenzo, G.-LongA, V. M. (1996). Introducción a la Sintaxis Generativa. Madrid: Alianza Universidad.

MenÉndez Pidal, R. (1968). Manual de Gramática Histórica Española. Madrid: Espasa-Calpe.

OrTEGa y Gasset, J. (1972). El Hombre y la Gente. Madrid: Espasa-Calpe.

PaUl, H. (1968). Prinzipien der Sprachgeschichte. Tübingen: Max Niemeyer Verlag.

VALIN, R. (ed.). (1982). Leçons de Linguistique de Gustave Guillaume 19481949. Grammaire particulière du français et grammaire générale (IV). Québec: Les Presses de l'Université Laval.

VAliN, R.-HiRTLE, W.-JolY, A. (eds.). (1985). Leçons de Linguistique de Gustave Guillaume 1945-1946. C. Grammaire particulière du français et grammaire générale (Y). Québec / Lille: Les Presses de l'Université Laval / Presses Universitaires de Lille.

VENDRYES, J. (1968). Le Langage. Introduction Linguistique à l'Histoire. París: Albin Michel. 